M. Polishchuk
Associate Professor
National Technical University of Ukraine
Department of Technical Cybernetics
Ukraine

M. Tkach
Associate Professor
$\begin{array}{r}\text { National Technical University of Ukraine } \\ \text { Department of Technical Cybernetics } \\ \text { Ukraine }\end{array}$

M. Polishchuk

rnetics

(1)

\section{Experimental Studies of Robotic Assembly of Precision Parts}

At present, robotization of assembly processes is achieved through the use of industrial robots with high positioning accuracy in conjunction with tactile means of adaptation to the conditions of assembly of precision parts. The cost of such robots is many times higher than the cost of simple robots with low positioning accuracy of the robot arm. The research in this article is aimed at reducing the cost of assembly processes for precision parts by applying the position correction of the connected parts not by the robot hand, but by an additional technological module that is installed on the manipulator of a simple robot and performs high-speed stochastic mismatch scan of assembly objects.

The article presents the results of a full factorial experiment of the process of joining precision cylindrical parts with a gap of no more than 3...5 microns. A regression model of this process is proposed, a formula for calculating the quasi-optimal modes of precision assembly and graphanalytical dependences of the assembly time on the scanning modes of the misalignment of assembly objects are given. The proposed high-speed method for compensating for the positioning error of an industrial robot makes it possible to assemble precision parts in a very short time within 1...3(s). The main economic effect of the research results is that the device for scanning the misalignment of assembly objects, which is installed on the arm of an inexpensive robot with a low positioning accuracy, can significantly increase the assembly speed and reduce capital investments in robotic assembly of high-precision parts.

Keywords: robotic assembly, precision connections, scanning path, vibration device.

\section{INTRODUCTION}

Theoretical and experimental research in the field of automation of assembly processes has been carried out for a long time, starting from the 90 s of the twentieth century and continues till the present. This is due to the difficulty of reaching a compromise between the solution of the problem of guaranteed connection of precision parts, on the one hand, and the use of automatic equipment with low cost, on the other hand. The use of modern industrial robots with high-precision digital drives for automation of assembly processes, as well as with elements of tactile adaptation to assembly conditions, greatly facilitates the solution of the problem of assembling precision joints. However, this solution is achieved by increasing a capital investment in the automation of assembly processes. In addition, even the use of an industrial robot with a high repeatability of movements up to $\pm 20 \mu \mathrm{m}$ does not guarantee $100 \%$ assembly of precision parts with a gap in the joint of no more than $3 \ldots 5 \mu \mathrm{m}$, but requires correction of the attached precise parts by appropriate programming. In this case, the movement of the robot arm position correction must occur at a relatively low speed in order

Received: September 2020, Accepted: November 2020 Correspondence to: Prof. Mikhail Polishchuk, Dep. of Technical Cybernetics, National Technical University of Ukraine "Igor Sikorsky Kyiv Polytechnic Institute", Kyiv, Ukraine. E-mail: borchiv@ukr.net doi: $10.5937 /$ fme2101044P

(C) Faculty of Mechanical Engineering, Belgrade. All rights reserved to avoid high dynamic loads. Additional time to correct the position of parts through special programming with micro movements of the robot arm reduces the productivity of assembly operations, which especially negatively affects the efficiency of mass production.

Therefore, assembly methods and devices for their implementation are needed that can correct (OR are needed to correct) the position of precision parts at high speed. But the main condition for ensuring the efficiency of assembly automation is that these assembly devices allow us to use a simple and inexpensive industrial robots with low positioning accuracy. This approach to solving the problem of assembling precision parts will significantly reduce the volume of capital costs for robotization of assembly processes in mass production.

The proposed article provides a methodology for experimental studies of the process of joining precision parts, describes the assembly device for correcting the relative position of the connected part, performs a statistical check of the obtained regression equation, namely, the function of the dependence of the highspeed assembly time on the scanning modes of the mismatch region of the assembly objects. The specified function was checked for its adequacy to the real process of pairing precision parts. The article presents nomograms for calculating quasi-optimal scanning modes for the mismatch zone of assembly objects. In conclusion, recommendations are given for the equipping simple and inexpensive industrial robots with 
an assembly device with low positioning accuracy of the robot arm, which makes it possible to reduce the financial costs of assembly processes using robots and thereby increase their economic efficiency.

\section{PREREQUISITES AND MEANS FOR SOLVING THE PROBLEM}

The need to automate assembly production is due to the following factors. Assembly processes are the final stage of the production process, at which the results of all previous stages of production are integrated and the main indicators of the quality of manufactured products are formed [1]. Assembly processes have a large share in the overall structure of the production of machines (25-40\%) and various devices (40-70\%), which is associated with a large volume of fitting work. In addition, as noted in [2], the calculation of the percentage of types of parts as assembly objects showed that $46 \%$ were assembly operations. Moreover, in real assembly processes, the errors in the relative position of parts may differ from batch to batch of parts and, as indicated in [3], in order to improve the productivity of the assembly process, first be compensated for errors in the location of the original part.

The use of industrial robots can increase labor productivity by 2-3 times, increase the efficiency of equipment operation and improve the rhythm of its operation [4]. That is why assembly robotization is the most promising direction in solving the problem of assembling precision joints. However, industrial robots have different positioning accuracy, i.e. not always predictable repeatability accuracy of the robot arm movement. This property poses the problem of ensuring a guaranteed connection of precision parts. To solve this problem, various approaches are used, both in terms of their efficiency and the cost of financial costs. For example, the efficiency of assembly processes can be increased as a result of optimal control of the robot arm [5] or by usage of laser sensors that are located in the arm of the robot and are designed to identify the position of assembly objects [6]. Both of these approaches are quite effective, but not for precision joints, which are characterized by very small joint tolerances, namely, within 4 ...10 microns. A distributed control method in a multiscale robotic assembly is presented [7] for the installation of large assembly parts with fasteners, such as an aircraft wing. But such connections have large enough gaps and tolerances. In such cases, running the robot assembly program in reverse order that can be an effective mechanism for eliminating assembly errors [8].

Assembly parts can have different geometric shapes. This fact also influences the choice of orientation method. So, the orientation of flat parts had been already described in some studies [9], a model of mixing parts was proposed, in which flat parts are periodically thrown by a simple throwing surface with one degree of freedom, captured and allowed to settle the parts in the desired position. Studies [10] prove the positive effect of increasing assembly accuracy on the efficiency and load capacity of robotic mechanisms. Improving assembly accuracy is especially important in the context of mass production, which is based on assembly lines of various types [11]. In this paper, three main types of assembly lines are considered and directions for their improvement are indicated.

For robotic assembly of cylindrical parts, studies [12] arose great interest, where the orientation of the part is determined using a vision system, and then a force or torque control algorithm is applied to perform assembly with tight tolerances. The angle of inclination of the part and the perpendicularity of one part relative to another are measured [13]. Both of the latter assembly methods are quite effective, but they require relatively expensive software and hardware in relation to simple robot manipulators. A dynamic model of the assembly of cylindrical parts taking into account the value of passive compliance, coefficient of inertia and friction are also already presented [14]. However, this model does not contain active influence on assembly objects.

In terms of actively influencing assembly parts while reducing the cost of robotic equipment, studies in this area have already generated interest [15]. This paper proposes a vibrating wrist with a defined vibration amplitude and trajectory. Experimental results have shown that wrist vibration can effectively compensate for large positioning errors of the robot arm. However, this paper does not provide any methods for calculating the vibrations of the robot's wrist. The use of lowfrequency vibration and adaptive grip of the robot arm has been proposed in another studies [16-18]. In these scientific works, active action is carried out by means of vibrations, which impart to the basic component of the assembly, and the component to be connected is placed in a gripper with elastic suspensions. However, it is known that when assembling large aggregates, the weight of the base component is often an order of magnitude greater than the weight of the component that is installed on the base aggregate. Therefore, from the point of view of energy, these technical solutions leave a reserve for their improvement.

In contrast to the above studies, the feasibility of actively influencing the assembly component that is installed on the assembly unit had been already shown [19]. Here, the effect is achieved through the use of the rotation of the robot gripper and the vibration device, however, in the presented mathematical model of the dynamics of the robotic assembly process, there are no analytical expressions for optimizing assembly modes. To increase the efficiency of assembly of the parts with guaranteed clearance, vibratory finders are used [20], which move one of the parts before joining them along a closed path. In this case, the trajectories can be rectilinear, elliptical, spiral, sinusoidal, etc. In addition, according to one more scientific research [21], criteria for analyzing search trajectories in the form of an Archimedes spiral and a sinusoid are proposed for adapting parts for automated assembly. In this case, preference is given to the scanning trajectory in the form of an Archimedes spiral. However, these works do not provide information on finding scanning modes and optimizing them. A promising direction in the robotization of assembly processes is the use of anthropomorphic robotic devices for the assembly of parts [22, 23], since this type of device has universal properties close to the human hand. However, these robots have a high cost and low VOL. 49, No 1, 2021 - 45 
productivity in performing technological operations, which is not very suitable for mass production.

Thus, the above analysis of robotic assembly systems leaves an urgent task of creating assembly devices for simple and inexpensive industrial robots with low positioning accuracy in conditions of mass production. The solution of this problem will significantly reduce the financial costs of robotic assembly of precision joints of parts.

\section{FORMULATION OF THE PROBLEM}

Depending on the accuracy standards in different countries of the world, precision joints include parts with dimensional accuracy in the range from 4th to 7 th accuracy grades. In practice, the permissible deviations from the nominal dimensions of parts are stochastic (probabilistic) in nature and their values are in the range from $2(\mu \mathrm{m})$ to $20(\mu \mathrm{m})$. Therefore, even when using expensive industrial robots with a high positioning accuracy of the robot arm up to $0.020(\mathrm{~mm})$, the assembly of such parts is impossible without preliminary correction of their relative position. In addition, the specified correction using precise digital drives is time consuming, which reduces productivity in a mass production environment.

In order to reduce the financial costs for robotic assembly of precision parts, it is necessary to create a device for correcting the position of assembly components for simple and inexpensive industrial robots. It is also necessary to subject the new device to experimental testing and to determine the quasi-optimal modes of its operation. Due to the lack of such studies, it is necessary to establish an extreme full factorial experiment. This experiment will allow not only to test the feasibility of using such devices, but also to search for optimal or quasi-optimal values of the factors that determine the efficiency of compensation for the mismatch of precision assembly objects.

\section{SOLUTION OF THE PROBLEM UNDER CONSIDERATION}

The objects of engineering and scientific novelty in the studies presented below are the design of an assembly device for an industrial robot for correcting the relative position of precision parts. The scientific novelty is represented by the graphical-analytical dependences of the scanning modes of the mismatch region of the exact parts, which were obtained as a result of the experiment, as well as nomograms for calculating the quasi-optimal modes of compensation for the mismatch of the assembly objects. In conditions of mass production, in order to ensure high productivity of the equipment, it is necessary to minimize the execution time of the technological operation. In this case, everything depends on the assembly time for precision parts. But the initial conditions for the assembly of parts with different tolerances of their sizes are stochastic (probabilistic) in nature. Therefore, to determine the stochastic influence of the mating modes of precision parts on the assembly time, it is necessary to provide a complete factorial experiment. For this purpose, an experimental stand was created, the schematic diagram of which is shown in Figure 1, and the general view of the stand is shown in Figure 2.

\subsection{Description of the experimental stand}

A simple and inexpensive robotic arm mod was used to transport precision parts from the storage to the assembly position MP-9S with three degrees of mobility in the $\mathrm{XYZ}$ coordinate system. On the hand 1 of this robot (see Figure 1), there is a device for compensating for the misalignment of assembly objects, namely, precision parts of the "shaft" type 2 and details of the tape "sleeve" 3.

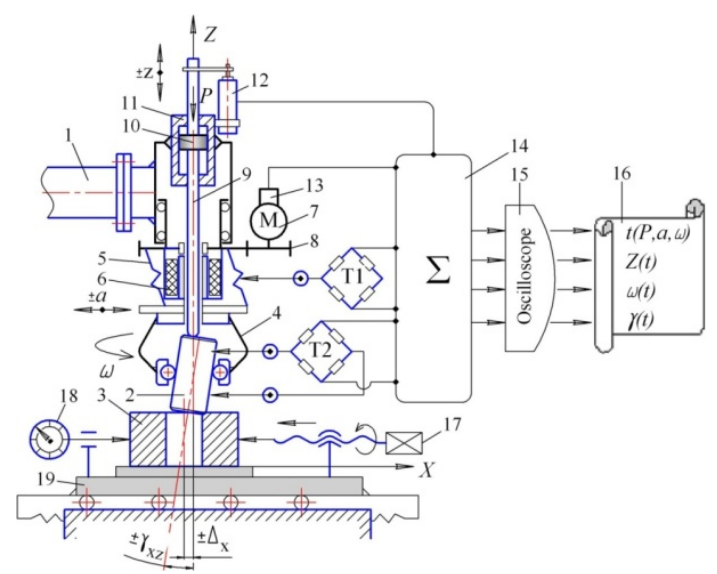

Figure 1. Schematic diagram of the experimental stand for assembling precision parts

When parts 2 are fed to the assembly position for connection with the base object 3 , there is always a stochastic mismatch $\Delta_{\Sigma}=\sqrt{\Delta_{x}+\Delta_{y}}$ in their relative position of the XY plane (where are the probabilistic errors in positioning the part along the $\mathrm{X}$ and $\mathrm{Y}$ coordinate axes), as well as a random skew angle of the part axes $\pm \gamma$ in different planes XYZ coordinate systems.

To compensate for the relative displacement $\Delta_{\Sigma}$ and skew angle of the axes $\pm \gamma$ of the parts, the gripper 4 , which is installed on spring hangers 5 and in which there is a part of the "shaft" type 2, is imparted two movements of scanning the mismatch region. Such movements are radial vibrations with amplitude of $\pm a$, from the electromagnetic vibrator 6 and rotational movement with an angular velocity $\omega$ from the electric motor 7 through the wheel gear 8 . Simultaneously, by means of the rod 9 with the piston 10 of the pneumatic cylinder 11 of part 2, a movement in the direction of the assembly along the $\mathrm{Z}$ axis with by $P$. Measurement of displacement in the direction of joining parts along the $\mathrm{Z}$ axis is carried out by an inductive displacement transducer 12 (see Figure 1), which is connected to a rod 9. The measurement of the amplitude of oscillations $\pm a$, reported by part 2 is carried out by resistor sensors of a tensometric bridge $\mathrm{T} 1$, and the measurement of a random skew angle $\pm \gamma$ of the axes of the parts occurs by means of a tensometric bridge T2. In addition, the rotation speed $\omega$ of the capture 4 is measured by the encoder 13, which is installed on the motor shaft 7. All of the above signals are transmitted for processing to the 
processor $\left(\sum\right) 14$ and then fed to the loop oscilloscope 15 to build oscillograms 16 of the assembly time $t$ functions $t(P, a, \omega)$, where: $P$ - assembly force, $a-$ vibration amplitude, $\omega$ - angular velocity of gripper rotation 4 .

The assembly effort $P$ was controlled by the pressure regulator in the pneumatic cylinder 11, the amplitude of the oscillations of the electromagnetic vibrator 6 was changed by the oscillator, and the change in the angular rotation speed $\omega$ of the engine 7 was carried out by changing its supply voltage. Oscilloscope 15 in real time $t$ produces graphs of changes in displacement $Z(t)$, speed $\omega(t)$ and skew angle of the axes of parts $\gamma(t)$. During the experiment, the initial misalignments of parts 2 and 3 , namely $\pm \Delta_{x}$ and $\pm \Delta_{y}$, were set using a micrometer screw 17 and were measured by an indicator 18 with an accuracy of a measuring scale of $2(\mu \mathrm{m})$, which are located in a coordinate device 19. According to the schematic diagram in Fig. 1, an experimental stand was created for assembling precision connections of the "shaft-sleeve" type, which is shown in Figure 2. An assembly device 2 with a rotating gripper 3 is installed on the arm 1 of an industrial robot for parts to be assembled with a base part of the "sleeve" type 4 . The base parts 4 are installed on a coordinate table 5 , which can move by the amount of misalignments $\pm \Delta_{x}$ and $\pm \Delta_{y}$ assembly objects in the $\mathrm{XY}$ plane in XYZ coordinate system. The magnitude of the mismatch $\pm \Delta_{x}$ and $\pm \Delta_{y}$ assembly objects was measured by micrometric indicators 6 mounted on racks 7. The movement of the part of the "shaft" type in the gripper 3 in the assembly direction along the $\mathrm{Z}$ axis is carried out by a pneumatic cylinder 8 with a rod 9 , which is connected to an inductive sensor 10 to control the movement of the part in the assembly direction.

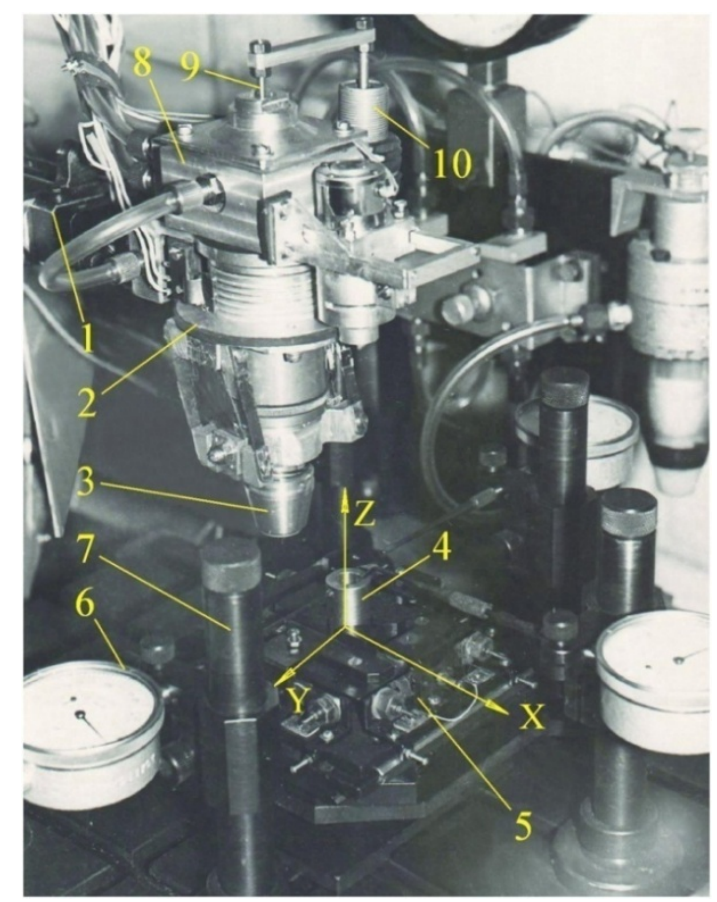

Figure 2. Experimental stand for robotic assembly of precision parts
The device for assembly is shown in more detail in Figure 3. As stated above, the assembly module is mounted on an industrial robot arm. The rod of the pneumatic cylinder imparts movement to the part in the gripper in the direction of assembly. An electric motor through a wheel transmission transmits a rotational motion to the gripper, and an electromagnetic vibrator imparts oscillatory movements to the gripper in the radial direction. Rotational and oscillatory movements of the gripper, which is installed on mechanical elastic suspensions, are necessary to compensate for the misalignment of the assembly objects.

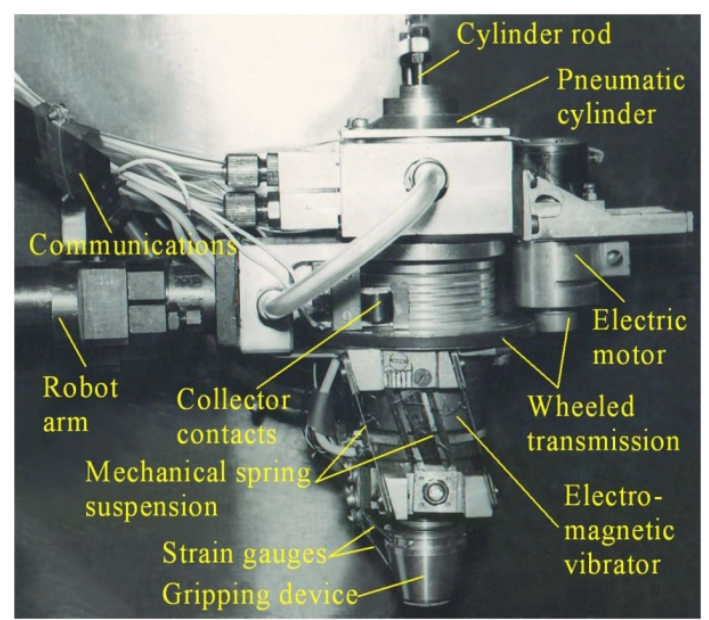

Figure 3. Module for assembling precision parts

Strain gauges measure the angle of misalignment of the axes of the parts and the magnitude of the vibration amplitude, which inform the gripper in order to compensate for the misalignment of the assembly objects. The signals of such measurements are sent to the processor for processing through the collector contacts and the corresponding communications (see also Figure 1).

\subsection{Method of experimental research}

Figure 4 shows a schematic diagram of a general shaftto-sleeve precision connection in the XYZ coordinate system. In the process of experiments, an industrial robot with a gripper (see Figure 4, a) an installed precision parts of the "shaft" type into parts of the "sleeve" type according to exact fits from the 5th to the 7 th precision grades. When joining parts, there is always a misalignment in the form of an angle of misalignment of the axes $\pm \gamma$ in different planes of the XYZ coordinate system and a linear misalignment $\pm \Delta$. These misalignments are the result of an error in the positioning of the robot arm, as well as a consequence of an error in the positioning of a part of the "sleeve" type. As a result of these mismatches, under the action of the assembly force $\mathrm{P}$, forces of normal reactions $\mathrm{N}$ and $\mathrm{N} 1$ arise at the points of contact of the parts, which cause the corresponding friction forces $\mathrm{kN}$ and $\mathrm{kN1}$ (where $\mathrm{k}$ is the coefficient of friction). These friction forces at critical values cause the parts to jam. To eliminate the indicated mismatch and eliminate the possibility of parts jamming, the robot's gripper was given a rotational movement with an angular velocity $\omega$ and 
oscillatory movements $\pm a$. At certain values of the frequencies of these movements, the attached piece of the "shaft" type scans the mismatch zone of the assembly objects within the limits $\pm \Delta_{\min } \ldots \pm \Delta_{\max }$ (Figure $4, \mathrm{~b})$. Scanning can be carried out along different trajectories. If the direction of the part positioning error is uncertain, it is preferable to use the trajectories in the form of a Guido Grandi rose with an amplitude and maximum scanning step $s_{i}$.

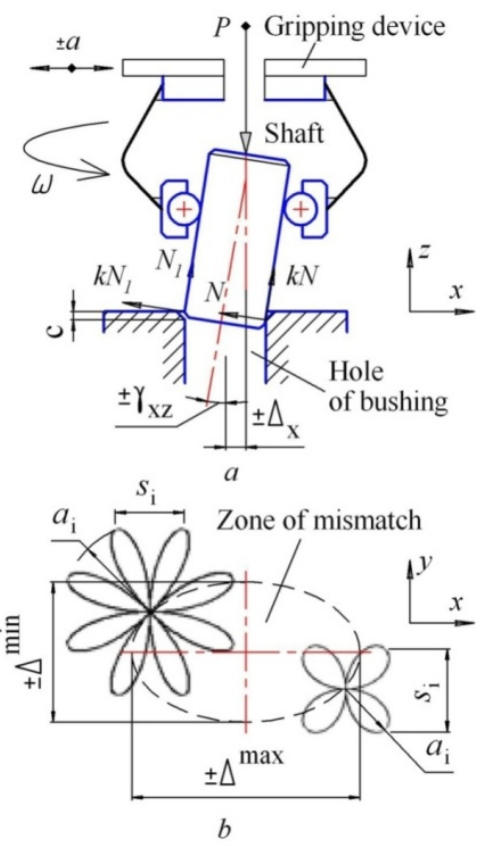

Figure 4. Scheme of precision connection of the general type "shaft-sleeve"

The scanning trajectory in the form of a rose shape by Guido Grandi is characterized by the equation $R=a_{i} \operatorname{Sin} \frac{m}{n} \varphi$, where: $R$ is the variable radius of the rose petals; $a_{i}$ - the radius of the circle of the rose; $\varphi$ is the angle of the vector of radius $R(\varphi=0 \ldots 2 \pi)$, the ratio $m / n$ determines the number of rose petals. For positive integer values $m$ and $n$, the number of rose petals is $m$ if both numbers are odd. If at least one number $m$ or $n$ is even, then the number of rose petals is equal to $2 \mathrm{~m}$. Changing the number of rose petals allows us to adjust the maximum step $s_{i}=s_{\text {imax }}$ (see Figure 4) of scanning the mismatch zone of assembly objects. The scanning step is defined as the length of the chord of the circle $2 a$, that is $s_{i}=2 a_{i} \sin (\alpha / 2)$ : where $\alpha-$ is the angle between the rose petals, which is equal to $\alpha=2 \pi /(m / n)$, i.e. determined by the number of rose petals. The maximum scanning step should not exceed the maximum clearance $\delta_{\max }$ in the shaft-to-sleeve connection, namely: $s_{\max } \leq \delta_{\max }=\left(D_{\max }-d_{\min }\right)$ where $D_{\max }, d_{\min }$ is the maximum diameter of the bushing hole and the minimum diameter of the shafttype part, respectively. The specific values of these parameters are determined by the quality of precision of precision parts according to the accuracy standards of a particular country.

\subsection{Building a regression model of the response function}

It is known that most of the response functions, i.e. functions of the influence of process factors on the optimization parameter, can be represented as a sum or product of independent factors. In technical systems, as a rule, the presentation of the response functions of an unknown model as a product of independent factors dominates. Therefore, as a hypothesis (which requires further confirmation) at the stage of setting the problem, we represent the objective function as a product of separate functions of independent variables:

$$
t=C_{0} f_{1}\left(P_{i}\right) f_{2}\left(\mathrm{a}_{i}\right) f_{3}\left(\omega_{i}\right) \rightarrow \min
$$

where: $t$ - optimization parameter, i.e. assembly time (s); $P$ - assembly force (N); $a$ - vibration amplitude (m); $\omega$ - angular speed of rotation of the robot gripper $(\mathrm{rad} / \mathrm{s}) ; i=1 \ldots \mathrm{n}$, where $\mathrm{n}$ is the number of the experiment.

A preliminary series of experiments (which for brevity is not presented here) and the analysis of factor dependences showed that the most likely image of function (1) is a function in the form of a product of power functions, namely:

$$
t=C_{0} P_{i}^{\alpha} a_{i}^{\beta} \omega_{i}^{\varepsilon} \rightarrow \min
$$

where: $C_{0}$ is a constant coefficient that reflects unaccounted factors; $\alpha, \beta, \quad-$ unknown exponents to be determined. However, this method of presenting the future objective function is hypothetical and is applied only to clarify the task of further research. Now the research task is to reduce the determining of numerical values of the parameters of function (2). For experimental studies, we will accept the following restrictions on parameters that are determined by industrial feasibility, namely:

$$
\begin{aligned}
& 6 \leq P \leq 65(H) ; \\
& 1 \leq a \leq 3\left(a \cdot 10^{-3}{ }_{M}\right) ; \\
& 2 \pi \leq \omega \leq 6 \pi(\mathrm{pa \partial} / \mathrm{s})
\end{aligned}
$$

According to the method of factorial experiments, the number of experiments is equal to $N=n^{k} m$, where: $n$ - is the number of levels of variation of factors; $k$ - is the number of factors; $m$ - is the number of repetitions of each experiment for good repeatability of the test results and reducing the variances of measurement errors. In our case, an $N=2^{3} 8=64$ experiment was carried out. Taking into account that the assumed dependence (2) is not linear in terms of factors, we logarithm it and bring it to a linear form:

$$
\ln t=\ln C_{0}+\alpha \ln P+\beta \ln a+\varepsilon \ln \omega
$$

and introduce the following notation:

$\ln t=\tilde{y} ; \ln C_{0}=b_{0} ; \alpha=b_{1} ; \beta=b_{2} ; \varepsilon=b_{3} ;$

$P=\tilde{x}_{1} ; a=\tilde{x}_{2} ; \omega=\tilde{x}_{3}$. Then the postulated empirical model (4) can be written as:

$$
\tilde{y}=b_{0}+b_{1} \ln \tilde{x}_{1}+b_{2} \ln \tilde{x}_{2}+b_{3} \ln \tilde{x}_{3}
$$


As it is known when planning factorial experiments, the function of the studied variables is an incomplete quadratic polynomial [24] (Plyaskin II, 1982), which we write when taking into account the interaction of factors and in coded variables:

$$
\begin{aligned}
& y=b_{0}+b_{1} x_{1}+b_{2} x_{2}+b_{3} x_{3}+b_{12} x_{1} x_{2}+ \\
& +b_{13} x_{1} x_{3}+b_{23} x_{2} x_{3}+b_{123} x_{1} x_{2} x_{3}
\end{aligned}
$$

where: $b_{0}$ - coefficient taking into account the influence of not specified factors; $b_{i, j, k}$ - constant coefficients for independent factors $x_{i, j, k} ; i, j, k=1,2,3$.

When planning factorial experiments, the coded values of the variables are used. This facilitates not only the calculation of constant coefficients, but also the study of the future regression model of the response function. Therefore, we use the linear transformation formula [25]:

$$
x_{i}=\frac{2\left(\ln \tilde{x}_{i}-\ln \tilde{x}_{i_{\text {max }}}\right)}{\ln \tilde{x}_{\dot{m}_{\text {max }}}-\ln \tilde{x}_{i_{\text {min }}}}+1
$$

where $\tilde{x}_{i}$ is the natural dimension of the variables. In a dimensionless coordinate system for an experimental model of the type $n^{k}=2^{3}$, the upper level corresponds to the factor value $+1(\max )$, the lower level -1 ( $\min )$, and the coordinates of the center of the experimental design coincide with the origin of the coordinate system.
Next, we pass from the coordinate system in physical dimension (3) $\tilde{x}_{1}, \tilde{x}_{2}, \tilde{x}_{3}$ to the dimensionless coordinate system $x_{1}, x_{2}, x_{3}$ (see table 1 ).

From this table, using formula (7), we find expressions for dimensionless variable factors:

$$
\begin{aligned}
& x_{1}=\frac{2\left(\ln \tilde{x}_{1}-4,174\right)}{4,174-1,792}+1=0,84 \ln \tilde{x}_{1}-2,5 \\
& x_{2}=\frac{2\left(\ln \tilde{x}_{2}-1,099\right)}{1,099-0}+1=1,82 \ln \tilde{x}_{2}-1 \\
& x_{3}=\frac{2\left(\ln \tilde{x}_{3}-2,936\right)}{2,936-1,838}+1=1,82 \ln \tilde{x}_{3}-4,35
\end{aligned}
$$

Table 2 displays the planning matrix for a full factorial experiment. The upper level corresponds to the maximum value of the factor $+(\max )$, the lower level ( $\mathrm{min}$ ) corresponds to the minimum value of the factor in natural units. In this case, the factors that affect the assembly time are: $P$ - assembly force $(\mathrm{N}) ; a$ - vibration amplitude of the robot gripper (m); $\omega$ - angular speed of rotation of the robot gripper $(\mathrm{rad} / \mathrm{s})$. The lower part of Table 2 demonstrates the planning of variations in the effects of interaction of factors.

Table 3 shows the results of experiments on the influence of scanning modes (see also Table 2) on the assembly time of parts. The vertical columns show theassembly time, and the horizontal strings show the replay results for each experiment. The last column $\bar{t}_{i}$ shows the average assembly times for precision parts.

Table 1. Levels of variation of independent factors

\begin{tabular}{|c|c|c|c|c|c|c|}
\hline \multirow{2}{*}{$\begin{array}{c}\text { Factors } \\
\text { levels }\end{array}$} & \multicolumn{2}{|c|}{ Force $P(\mathrm{~N})$} & \multicolumn{2}{c|}{$\begin{array}{c}\text { Vibration amplitude } \\
a \cdot 10^{-3}(\mathrm{~m})\end{array}$} & \multicolumn{2}{c|}{$\begin{array}{c}\text { Angular velocity } \\
\omega(\mathrm{rad} / \mathrm{s})\end{array}$} \\
\cline { 2 - 7 } & $\tilde{x}_{1}$ & $\ln \tilde{x}_{1}$ & $\tilde{x}_{2}$ & $\ln \tilde{x}_{2}$ & $\tilde{x}_{3}$ & $\ln \tilde{x}_{3}$ \\
\hline Upper +1 & 65 & 4,174 & 3 & 1,099 & $6 \pi$ & 2,936 \\
Basic 0 & 35,5 & - & 2 & - & - & - \\
Lower -1 & 6 & 1,792 & 1 & 0 & $2 \pi$ & 1,838 \\
\hline
\end{tabular}

Table 2. Extreme Experiment Planning Matrix

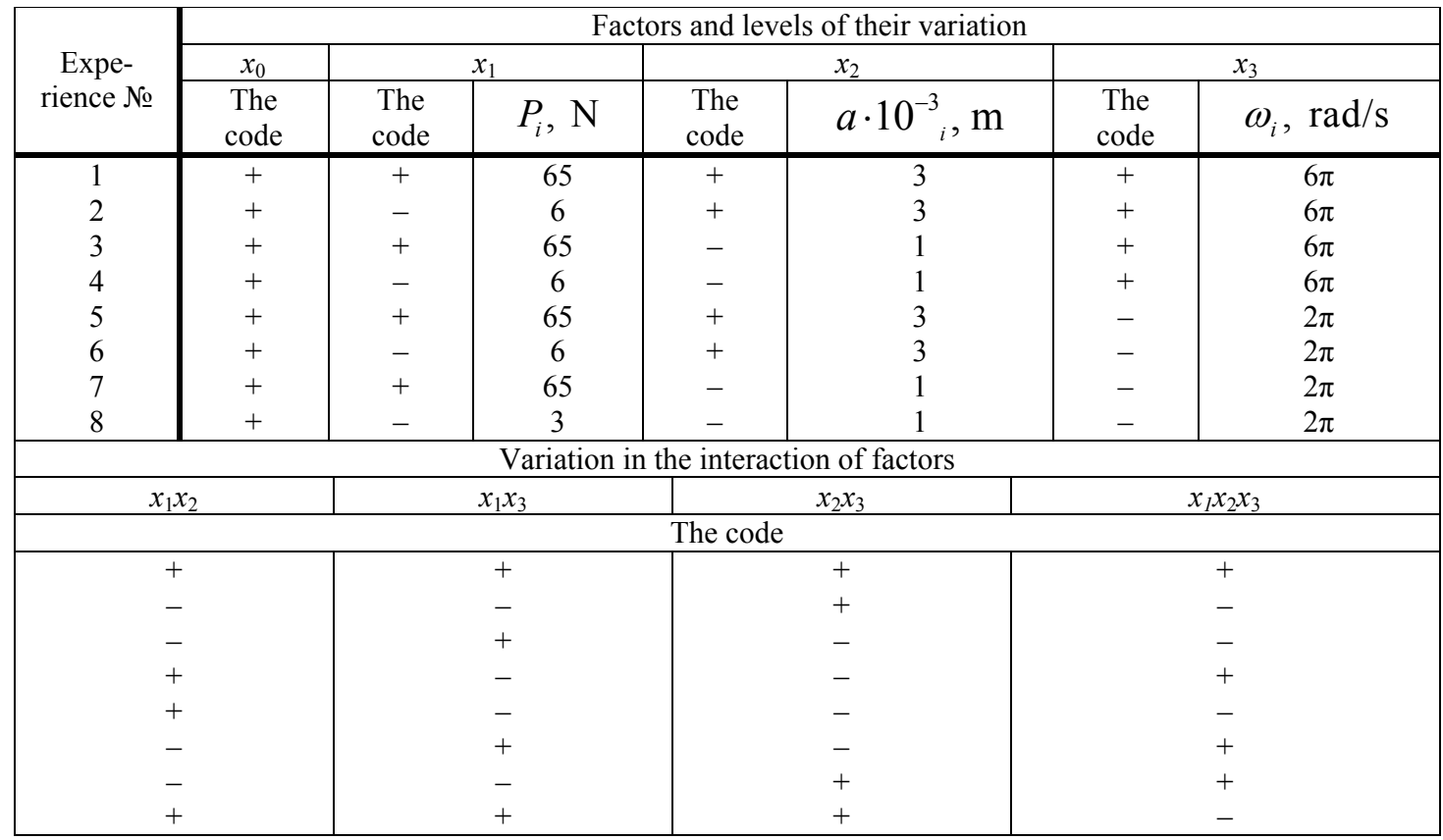


Table 3. The results of the experiment

\begin{tabular}{|c|c|c|c|c|c|c|c|c|c|}
\hline \multirow{2}{*}{$\begin{array}{c}\text { Expe- } \\
\text { rience } \\
\text { № }\end{array}$} & \multicolumn{10}{|c|}{ Assembly time $t$ (by the number of repetitions of experiments $m \rightarrow t_{1} \ldots t_{8}$ ) } & Averages \\
\cline { 2 - 11 } & $t_{1}$ & $t_{2}$ & $t_{3}$ & $t_{4}$ & $t_{5}$ & $t_{6}$ & $t_{7}$ & $t_{8}$ & $\bar{t}_{i}$ \\
\hline 1 & 1,78 & 1,45 & 1,58 & 1,32 & 1.44 & 1,70 & 1,52 & 1,34 & 1,52 \\
\hline 2 & 1,14 & 1,32 & 1,16 & 1,20 & 1,12 & 1,04 & 1,20 & 0,98 & 1,15 \\
\hline 3 & 0,38 & 1,06 & 1,18 & 0,98 & 1,02 & 1,14 & 1,19 & 1,26 & 1,10 \\
\hline 4 & 1,10 & 1,04 & 0,94 & 1,16 & 0,90 & 1,06 & 0,92 & 1,04 & 1,02 \\
\hline 5 & 2,75 & 2,26 & 2,18 & 2,05 & 2,28 & 2,24 & 2,44 & 2,32 & 2,34 \\
\hline 6 & 1,84 & 1,74 & 1,54 & 1,72 & 1,78 & 1,42 & 1,48 & 1,70 & 1,65 \\
\hline 7 & 1,30 & 1,50 & 1,08 & 1,22 & 1,34 & 1,38 & 1,10 & 1,18 & 1.27 \\
\hline 8 & 1,15 & 1,24 & 0,95 & 0,88 & 1,24 & 1,10 & 1,18 & 1,04 & 1,09 \\
\hline
\end{tabular}

The obtained data make it possible to determine the numerical values of the constant coefficients in equation (6). Due to the fact that the full factorial experiment refers to orthogonal designs, the calculation of the regression coefficients is greatly simplified. According to the formula [24], the coefficients of the regression equation can be determined as:

$$
b_{i}=\frac{\sum_{i=1}^{n} x_{i} \bar{y}_{i}}{m}
$$

where: $i-$ is the experience number; $m-$ is the number of test points in the plan; $\bar{y}_{i}-$ the average response of function (6) by the number of repeated experiments at the corresponding point in the matrix of the experimental design. Having calculated, thus, the values of the coefficients and substituting them into equation (6), we obtain the regression equation:

$$
\begin{aligned}
& y=0,3+0,108 x_{1}+0,183 x_{2}-0,125 x_{3}+ \\
& +0,05 x_{1} x_{2}-0,017 x_{1} x_{3}-0,073 x_{2} x_{3}- \\
& -0,0025 \cdot 10^{-2} x_{1} x_{2} x_{3}
\end{aligned}
$$

Next, a standard statistical analysis of the experimental results was carried out. Statistical analysis according to the method that was applied [24], included checking the homogeneity of the variances of the experimental data in Table 3 by the Cochran test. Then the significance of the coefficients of the regression equation was checked using the Student's t-test, and the adequacy of the model of the real process was checked according to the well-known Fisher criterion [25]. As a result of this statistical analysis, the final version of the regression model (10) of the parts assembly process took the following form:

$$
\begin{aligned}
& y=0,3+0,108 x_{1}+0,183 x_{2}-0,125 x_{3}+ \\
& +0,05 x_{1} x_{2}-0,073 x_{2} x_{3}
\end{aligned}
$$

The coefficients for paired interaction of factors $x_{1} x_{3}$ and for triple interaction of factors $x_{1} x_{2} x_{3}$ in equation (10) after checking the significance of the coefficients of the regression equation using the Student's t-test turned out to be insignificant. Therefore, they were excluded from the regression equation (10). The resulting regression model for the assembly of precision parts allows one to study the influence of independent factors of the response function on the optimization parameter, i.e. assembly time. Equation (11) in coded variables shows the statistical relationship between the optimization parameter - assembly time and the factors, i.e. modes of scanning the mismatch zone of the parts. By analyzing the value and sign of each regression coefficient (11), it is possible to obtain reliable information (since the adequacy of the model was verified by Fisher's criterion) about the influence of factors on the optimization parameter and to develop a strategy for finding the extremum of the objective function. In equation (11), the coefficients of the variables $x_{1}$ and $x_{2}$ are positive. This means that an increase in the assembly force and vibration amplitude of the robot gripper causes an increase in the assembly time of the parts. In this case, the vibration amplitude of the robot's grip has a dominant influence, because $b_{2}=$ $0,183>b_{1}=0,108$.

The negative sign of the coefficient at the factor $x_{3}$ that reflects the rotation speed of the gripper (and hence the scanning speed of the mismatch zone of the assembly objects) indicates that an increase in the scanning speed causes a decrease in the assembly time. The regression coefficient $b_{12}=0,05$ in equation (11) with interaction factors shows that the assembly time (more precisely $y=\ln t$ ) will increase if the factors $x_{1}$ and $x_{2}$ (i.e., the assembly effort and vibration amplitude) are simultaneously at the upper or lower levels of their values (see also Table. 1). The opposite effect takes place with a pair interaction of factors $x_{2} x_{3}$ (amplitude and speed of rotation), because $b_{23}=-0,073<0$. This means that the parameter $y=\ln t$ (build time code) decreases if both factors are at the upper or lower levels, i.e. have a maximum or minimum value. Next, let us compare these effects with the analysis of oscillograms that were obtained during the experiment in real time.

\subsection{Analysis of oscillograms of the assembly of parts}

As it was shown above in the diagram of Figure 1, the experimental stand included an oscilloscope, which recorded the change in the coordinate of movement of the "shaft" type part depending on the assembly force, the rotation speed of the robot gripper and the amplitude of its oscillations. The obtained oscillograms (see Fig. 5) show three processes of assembling a part of the "shaft" type with a part of the "sleeve" type according to the fit $ø 10 \mathrm{H7/h6}$. As we know, deviations of the nomi- 
nal dimensions of parts have a stochastic (probabilistic) nature. The permissible maximum deviations for the specified fit of the parts are: the maximum allowable gap in the shaft-sleeve connection $\delta_{\max }=24 \mu \mathrm{m}$, and the minimum allowable gap $\delta_{\max }=0 \mu \mathrm{m}$. In the test batch of 64 pairs of parts, the joint gap was in the range of $\delta_{i}=$ 4 ...18 microns.

On all three oscillograms (see Figure 5), graphs 1 illustrate the movement of the shaft into the bushing in the direction of the $\mathrm{Z}$ coordinate axis, graphs 2 show the angular speed of rotation of the robot gripper, and graphs 3 show the change in the angle $\pm \gamma$ of the relative skew of the axes of the parts. For the first assembly cycle (see Fig. 5 , a), the assembly modes were: assembly force of contact of parts $P_{\max }=65(\mathrm{~N})(\mathrm{N})$; vibration amplitude of the robot gripper $a_{\max }=\Delta_{\max }=3 \cdot 10^{-3}(\mathrm{~m})$, where $\Delta_{\max }$ is the maximum misalignment error of parts; the angular speed of rotation of the robot gripper $\omega=4 \pi(\mathrm{rad} / \mathrm{s})$, which provided scanning of the mismatch zone with a scanning step of $s_{\min }=[\delta]=4 \mu \mathrm{m}$.

As can be seen from the oscillogram in Figure 5(a), in the section c- $d$ of curve 1 , there is no shaft movement in the direction of the $\mathrm{Z}$ coordinate, which corresponds to the contact of the parts along the ends. At this stage of the assembly, the mismatch zone of the assembly objects is scanned. Further, in the section $\mathrm{d}-\mathrm{e}$, the part of the "shaft" type under the action of the assembly force P moves in the area of the sleeve chamfer, i.e. the shaft is centered relative to the bushing axis. This is evidenced by the change in the angle $\pm \gamma$ of the relative skew of the axes of the assembly parts.

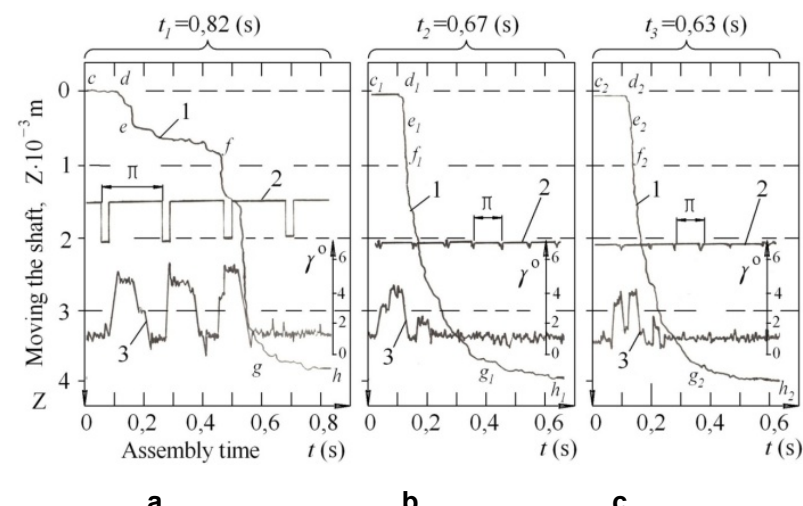

Figure 5. Oscillograms of assembly cycles of precision parts shaft-sleeve type:

a) $P_{\max }=65(\mathrm{~N}) ; a_{\max }=\Delta_{\max }=3 \cdot 10^{-3}(\mathrm{~m}) ; \omega=4 \pi$ $(\mathrm{rad} / \mathrm{s})$;

b) $P_{\max }=25(\mathrm{~N}) ; a_{\min }=\Delta_{\min }-[\delta]=1 \cdot 10^{-3}(\mathrm{~m})$; $\omega=6 \pi(\mathrm{rad} / \mathrm{s})$;

c) $P_{\max }=6(\mathrm{~N}) ; a_{\min }=\Delta_{\min }-[\delta]=1 \cdot 10^{-3}(\mathrm{~m})$; $\omega=6 \pi(\mathrm{rad} / \mathrm{s})$.

But in the section e-f of curve 3, there is a sharp decrease in the speed of the shaft advance, almost to zero. This is a consequence of temporary jamming of the shaft in the sleeve due to the excessive angle $\pm \gamma$ for this stage of the relative skew of the axes of the parts (see curve 3, Figure 5,a). However, already after turning the robot gripper through an angle of $2 \pi$ (see curve 2 ), which means that the elastic suspension vector of the robot's gripper changes, and also as a result of scanning the error zone, the shaft in the $\mathrm{f}-\mathrm{g}$ section moves again in the direction of the $\mathrm{Z}$ axis. A sharp decrease in the angle $\pm \gamma$ of the relative skew of the axes of the parts, almost to zero. Section $\mathrm{g}-\mathrm{h}$ corresponds to the final installation of the shaft into the sleeve. Assembly time of parts was $t_{1}=0,82(\mathrm{~s})$.

For the other two assembly cycles, the scanning modes were changed, namely: the assembly force $P_{\text {max }}=25(\mathrm{~N})$ in Figure $5(\mathrm{~b})$ and $P_{\max }=6(\mathrm{~N})$ in Figure 5(c), and also increased the angular velocity of rotation of the robot gripper to the maximum value $\omega=6 \pi(\mathrm{rad} / \mathrm{s})$. The result of these changes was a decrease in assembly time, respectively $t_{2}=0,67$ (s) and $t_{3}=0,63$. Comparison of the portions of curve $d_{1}-e_{1}-$ $f_{1}$, which illustrate the movement of a part of the "shaft" type in Fig. 5 c, similar areas curve $d_{2}-e_{2}-f_{2}$ in Fig. 5b, indicates the possibility of guaranteed elimination of the temporary jamming phenomenon. This effect indicates the existence of quasi-optimal scanning parameters for the mismatch zone of assembly components. The difference in time between the last two assembly cycles was $5.97 \%$. This testifies good repeatability of the experiments and admissible variances of measurement errors. Homogeneity of dispersions of the experimental data in Table 3 is performed according to the wellknown Cochran's criterion. As it was noted above, the number of experiments was $N=n^{k} m=2^{3} 8=64$, where: $n$ - the number of levels of variation of factors; $\kappa-$ is the number of factors; $m-$ is the number of repetitions of each experiment for good repeatability of the test results and reducing the variances of measurement errors.

Thus, the analysis of the oscillograms of assembly cycles confirms the above remarks about the influence of the coefficients of the regression equation (11) on the optimization parameter - assembly time. This fact allows us to make a preliminary conclusion: the minimization of the objective function (2) is possible with a decrease in the scanning amplitude, assembly effort and a simultaneous increase in the angular velocity of rotation of the robot gripper. The data obtained make it possible to determine the direction of the search for quasi-optimal assembly modes, but do not make it possible yet to determine their specific values. To solve this problem, it is necessary to transform the regression equation (11) into a function of the dependence of the assembly time on the modes in natural measurement of parameters. For this purpose, we substitute the coded values of the variables (8) into the regression equation (11) and, after transformation, we obtain the equation:

$$
y=\ln \left(e^{0,198} \frac{\tilde{x}_{1}^{0,0487}}{\tilde{x}_{3}^{0,0947}} \tilde{x}_{2}^{\left(0,683+\ln \left(\frac{\tilde{x}_{1}^{0,0764}}{\tilde{x}_{3}^{0,242}}\right)\right)}\right)
$$


Considering that $y=\ln t ; \quad \tilde{x}_{1}=P ; \quad \tilde{x}_{2}=a$; $\tilde{x}_{3}=\omega$ after potentiating (12), we obtain the function of the assembly time $t$ in natural measurement of the variables $\mathrm{P}, \mathrm{a}, \omega$, namely:

$$
\left.t=1,219 \frac{P^{0,0487}}{\omega^{0,0947}} a^{(0,683+\ln }\left(\frac{P^{0,0764}}{\omega^{0,242}}\right)\right)
$$

The condition for the existence of an extremum of the objective function (13) at some point of the factor space with coordinates $\left(P_{0}, a_{0}, \omega_{0}\right)$ has the form:

$$
\frac{\partial t}{\partial P}\left(P_{0}\right)=\frac{\partial t}{\partial a}\left(a_{0}\right)=\frac{\partial t}{\partial \omega}\left(\omega_{0}\right)
$$

To find the coordinates of the extremum of this function, it is necessary to determine the partial derivatives with respect to each variable. From the analysis of expressions of partial derivatives, it becomes obvious that they retain their sign in the range of accepted permissible values (3):

$$
\frac{\partial t}{\partial P}>0 ; \frac{\partial t}{\partial a}>0 ; \frac{\partial t}{\partial \omega}<0
$$

It is not difficult to make sure that expression (14) in our case is not satisfied, and expression (15) indicates the existence of extreme (more precisely, quasi-optimal) values of variables on the boundary of the factor space. In other words, the minimization of the assembly time will take place with a decrease in the assembly force $P$ and the scanning amplitude $a$, as well as with an increase in the angular velocity $\omega$ of rotation of the robot gripper. To determine the quasi-optimal assembly modes, it is advisable to solve the optimization problem analytically as a problem for the conditional extremum of the objective function (13) by finding the minimum value of the optimization parameter at the boundaries of the factor space. For this purpose, we transform the expression of the response function (11) into the canonical form of the second-order surface equation, which is the geometric image of the response function. To determine the type of this surface, it is enough to compose and determine the invariants according to this method [26].

These invariants are functions of constant coefficients of the regression equation (11) and determine the properties of the response surface regardless of its position in the factor space. The actual calculation of invariants is classical, therefore, we do not present it here, but offer the result. After performing the corresponding transformation method, we obtain the canonical form of the regression equation (11) in the form of a hyperbola equation in the plane of the coordinate system $0 x_{2} x_{3}$, provided that the assembly force $x_{1}=-$ parameter in equation (11), i.e. corresponds to the minimum value of the assembly force:

$$
\frac{x_{2}^{2}-x_{3}^{2}}{27,4\left(3,45 \cdot 10^{-3}+y\right)}=1
$$

In equation (16), the square of the length of the semi-axis of the hyperbola contains the optimization parameter $y=\ln t$. If we assign different values to this parameter and determine the coordinates $0 x_{2} x_{3}$ of the vertices of the family of hyperbolas in the coordinate system, then we obtain the isolines of the twodimensional section $\mathrm{A}-\mathrm{A}$ of the surface of the response function in Fig. 6. As seen from the section in Fig. 6(b) the shortest assembly time takes place at $x_{2}=-1$, $x_{3}=+1$, i.e. at the minimum scanning amplitude and maximum angular speed of rotation of the robot gripper. Comparing the coded values of the factors with their natural measurement (see Table 1), we find quasioptimal assembly modes, namely:

$$
P=P_{\min } ; a_{i}=a_{\min }=\Delta_{\Sigma}-[\delta] ; \omega=\omega_{\max }
$$

where: $\Delta_{\Sigma},[\delta]$ - respectively, the total mismatch error of the assembly objects and the tolerance for the assembly of parts according to the accuracy quality.
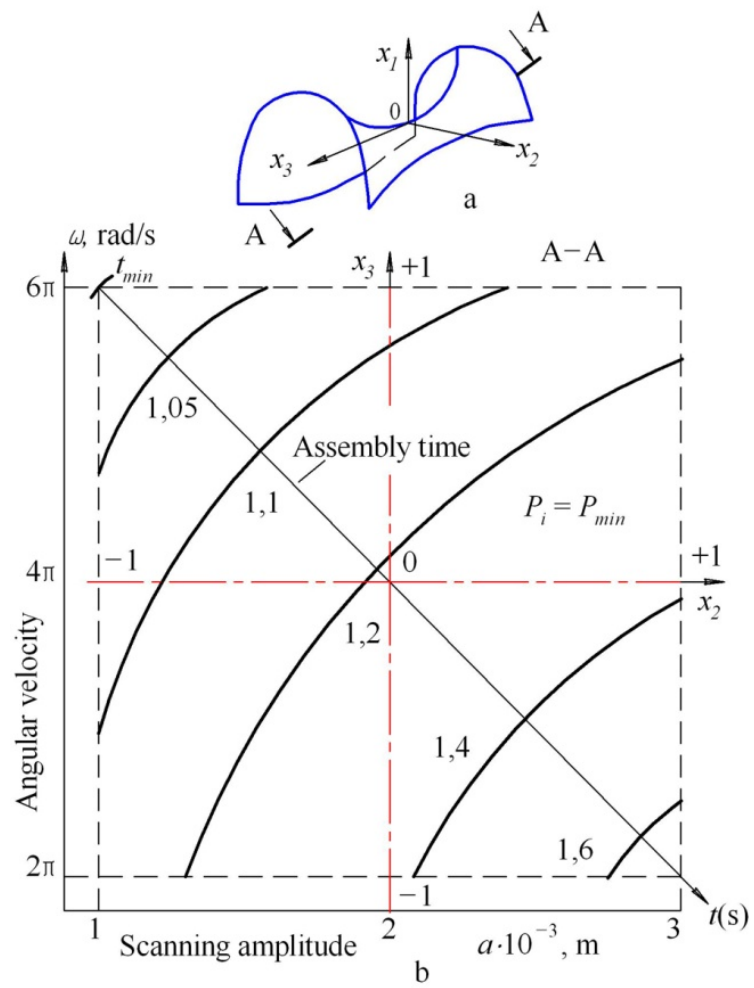

Figure 6. Geometric interpretation of the response function (11):

a - minimax type surface: hyperbolic paraboloid; b isolines of the two-dimensional section of the surface of the response function.

\subsection{Numerical analysis of assembly modes}

In Figure 7 are shown the graphs of the change in the assembly time from the values of the assembly force at the minimum scanning amplitude of the mismatch zone of the assembly parts. In Figure 8 are shown the same graphs, but at the maximum scanning amplitude. It can be seen from these graphs that the difference in the increase in assembly time at the minimum scanning amplitude $a_{i}=a_{\min }$ of the mismatch zone is $5 \%$. In the 
same range of values of the assembly force and angular velocities of rotation of the robot gripper at the maximum scanning amplitude $a_{i}=a_{\max }$, the increase in assembly time is $18.7 \%$. This effect confirms the dominant influence of the scanning amplitude on the assembly time of parts. Therefore, it is necessary to assemble precision parts with the minimum scanning amplitude and the maximum possible angular speed of rotation of the robot gripper. The scan amplitude should be limited by the inequality $a_{\min } \geq \Delta_{\Sigma}$.

In other words, the scanning amplitude cannot be less than the probable total mismatch error of assembly objects. The maximum angular velocity should be limited by the ratio $s_{\max } \leq[\delta]$ (see Fig. 4 and Fig. 9). This inequality indicates that the maximum scanning step should not exceed the tolerance for assembling parts according to the corresponding accuracy class. For engineering calculations of quasi-optimal assembly modes, it is convenient to use the nomogram in Fig. 9.

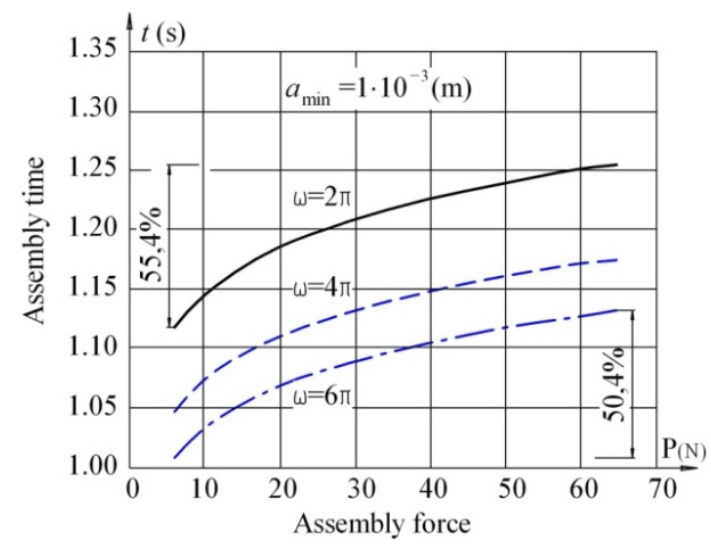

Figure 7. Graphs of the change in the assembly time $t$ from the values of the assembly force $P$ at the minimum scanning amplitude $a_{i}=a_{\min }$

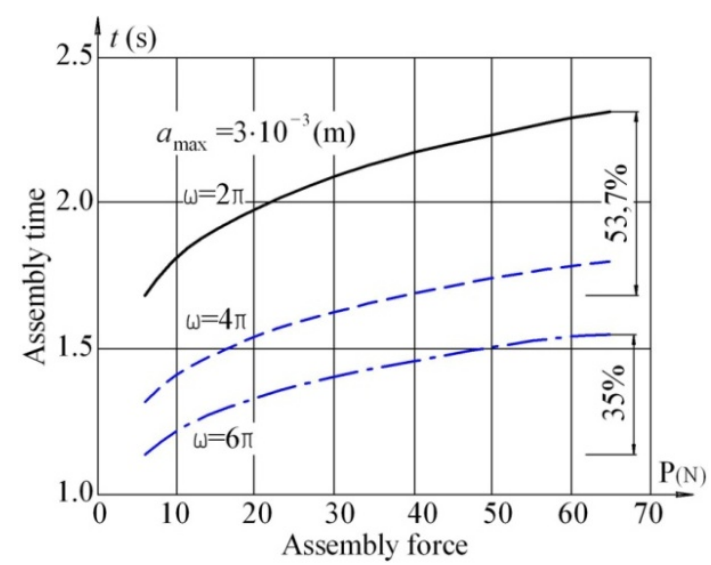

Figure 8. Graphs of the change in the assembly time $t$ from the values of the assembly force $P$ at the maximum scanning amplitude $a_{i}=a_{\max }$

According to the code of the nomogram, to calculate the minimum assembly time $t$, we have to perform the following steps for an arbitrary example.

The dotted line shows an arbitrary example of the assembly time calculation. Suppose, for example, the assembly force is $P=45(\mathrm{~N})$, the scanning amplitude is $a=2,4 \cdot 10^{-3}(\mathrm{~m})$, and the angular rotation speed of the robot gripper is $\omega=4 \pi(\mathrm{rad} / \mathrm{s})$, then according to the nomogram (see Fig. 9) the assembly time will be $t=1$,
47 (c). When the assembly time is limited by the technological process, then we perform the opposite actions, namely: from a given time, we determine the assembly modes. The upper part of the nomogram shows an example of the scan trajectory of the mismatch zone of assembly parts. As indicated above, the maximum scanning step $s_{\max } \leq[\delta]$ should not exceed the tolerance $[\delta]$ for joining parts according to the corresponding accuracy class. The scanning step is determined by the formula $s_{i}=2 a_{i} \operatorname{Sin}(\alpha / 2)$, $\alpha=360^{\circ} / k$, where: $a_{i}$ - scanning amplitude; $\alpha-$ is the central angle between rose petals; $k$ - is the number of rose petals (see above). For a more accurate time calculation, it is recommended to use the formula (13), which allows us to determine the minimum assembly time depending on the parameters: assembly force, scanning amplitude and angular speed of rotation of the industrial robot gripper.

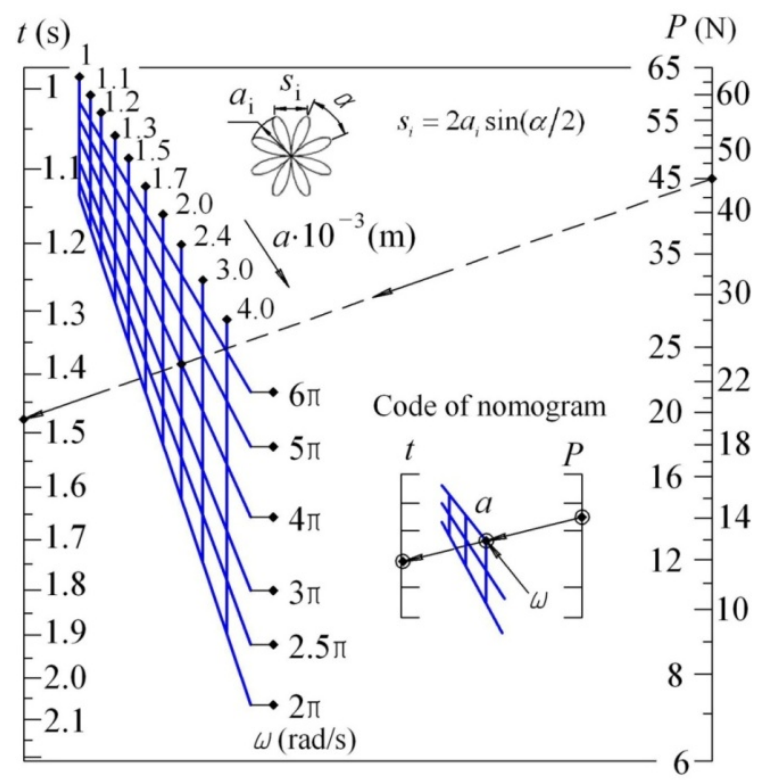

Figure 9. Nomogram for determining the assembly time of precision parts

\section{RESULTS AND DISCUSSION}

In contrast to the robotic assembly methods that were described in Section 2, the proposed method and device make it possible to automate the assembly of precision joints based on simple and inexpensive industrial robots, i.e. robots that have low positioning accuracy. The cost of such industrial robots is at least half of the cost of expensive robots with high-precision digital drives. At the same time, the cost of the assembly device itself to compensate for the positioning error of parts does not exceed $15 \% \ldots 20 \%$ of the cost of a simple robot or an automatic manipulator.

The executed experimental studies confirm the feasibility of usage of the developed assembly device for industrial robots with a low positioning accuracy of the robot arm. Statistical verification of the results of the experiment (see Table 3) and the obtained regression model (11) of the assembly process according to the Cochran's, Student's and Fisher's criteria allow us to 
assert the adequacy of the regression model to the real assembly process. The geometric interpretation of the regression model of the assembly process shows the minimax nature of the response function surface. This means that the quasi-optimal values of the assembly modes are at the boundaries of the factor space.

The stated research results were obtained due to the formulation of a full factorial experiment to optimize technical solutions, that is, when the variation of the investigated parameters (in this case, assembly modes) is carried out at the extreme extreme levels: $\min$ and $\max$, and their average value is in the center of the coordinate system of the parameter change. This method [24, 25] allows obtaining target functions of technological parameters, for example, as a proposed function (13). For such functions, engineers can calculate, if not optimal values, then at least quasi-optimal values of optimization parameters. This result should be considered sufficient for technological processes in mechanical engineering, because it contributes to a significant increase in productivity, in this case, assembly processes.

\section{CONCLUSION}

In this article, the authors have proposed a high-speed method to compensate for the positioning error of an industrial robot. The developed assembly device, which is installed on the robot arm, allows the assembly of precision parts in a very short time within $1 . . .3(\mathrm{~s})$. This effect of the proposed method is very important for the conditions of mass production of various precision instruments and machines.

As evidenced by the results of experimental studies, the assembly of precision parts at minimum values of the scanning amplitude (however, provided that $a_{\text {min }} \geq \Delta_{\Sigma}$ i.e., the amplitude must be equal to or greater than the robot positioning error) and the minimum assembly effort $P_{i}=P_{\min }$, as well as at the maximum possible angular speed of $\omega_{i}=\omega_{\max }$ rotation grabbing a robot, a significant reduction in assembly time is achieved. Namely, for precision parts applied to mechanical engineering, the time $t_{\max }$ of their assembly does not exceed $t_{\max } \leq 3(\mathrm{~s})$, which is several times less than the assembly time when industrial robots with expensive digital drives are used.

The obtained graphical-analytical dependences are the result of experimental studies provide an opportunity for engineers in the field of robotization of highprecision assembly processes to design such devices for compensating for positioning errors. The proposed analytical model of the interconnection between the assembly time and its modes, and the developed nomograms are recommended for calculation of quasioptimal parameters of the assembly of precision parts.

Ultimately, the results of this research can significantly reduce the financial costs of precision assembly through the use of inexpensive industrial robots with low positioning accuracy. This, in turn, provides an opportunity to increase the productivity of precision parts assembly and increase the efficiency of assembly processes in the context of mass production.

\section{DECLARATION OF CONFLICTING INTERESTS}

The author(s) declared no potential conflicts of interest with respect to the research, authorship, and/or publication of this article.

\section{REFERENCES}

[1] Shandrov B.V., Chudakov A.D. (2007). Technical means of automation Moscow: Publishing center "Academy", 2007, pp. 1-3.

[2] Ellekilde L-P, Buch J.P. et al. (2016). Industrial Assembly Cases. Technical Reports - Maersk McKinney Moller Institute, University of Southern Denmark, No. 1, pp. 21-22.

[3] Chen H., Xu J., Zhang B. and Fuhlbrigge T. (2017). Improved parameter optimization method for complex assembly process in robotic manufacturing. Industrial Robot, Vol. 44 No. 1, pp. 21-27. https://doi.org/10.1108/IR-03-2016-0098

[4] Ioppa A.V. and Moyzes B.B. (2008). Equipment and devices for automation of mechanical assembly production: a tutorial. Tomsk, 2008. pp. 2-3.

[5] Kartashev V.A. (2000). Manipulation systems assembly movement control. Abstract of dissertation for the degree of Doctor of Physics and Mathematics. Keldysh Institute of Applied Mathematics M.V. Moscow, 2000. 46 p.

[6] Pikalov A.A. (2014). Application of robotic systems in the assembly of aircraft structures. Branch of Irkut Corporation, Ulyanovsk, p. 1550-1555.

[7] Dogar M. et al. (2015). Multi-scale assembly with robot teams, The International Journal of Robotics Research, 34(13), pp. 1645-1659. doi: 10.1177/0278364915586606.

[8] Laursen J., Ellekilde L., Schultz U (2018). Modelling reversible execution of robotic assembly. Robotica, 36(5), 625-654, doi:10.1017/S0263 574717000613.

[9] Murphey T.D. and Lynch, K.M. (2008). Case Studies in Planar Part Feeding and Assembly Based on Design of Limit Sets, The International Journal of Robotics Research, 27(6), pp. 693-708. doi: 10.1177/0278364908090950.

[10]M. Penčić, M. Čavić, B. Borovac. Development of the Low Backlash Planetary Gearbox for Humanoid Robots. FME Transactions. Volume 45, 1, 2017. pp. 122-123.

[11] A.Deepak, R. Srivatsan, V. Samsingh. A Case Study on Implementation of Walking Worker Assembly Line to Improve Productivity and Utilisation of Resources in a Heavy Duty Manufacturing Industry. FME Transactions (2017) 45, 496-502.

[12] Chen H., Zhang G., Zhang, H., Fuhlbrigge, T.A. (2007). Integrated robotic system for high precision assembly in a semi-structured environment, Assembly Automation. 27 (3), 247-252 (2007). DOI: 10.1108/01445150710763277

[13] Wang, L., Sun, C., Tan, J., Zhao, B. and Wan, G. (2015). Improvement of location and orientation tolerances propagation control in cylindrical comp- 
onents assembly using stack-build assembly technique, Assembly Automation, Vol. 35 No. 4, pp. 358-366. https://doi.org/10.1108/AA-03-2015-023

[14] Pitchandi, N., Subramanian, S.P. and Irulappan, M. (2017). Insertion force analysis of compliantly supported peg-in-hole assembly, Assembly Automation, Vol. 37 No. 3, pp. 285-295, https: //doi.org/10.1108/AA-12-2016-167

[15] Jeong, K.W. and Cho H.S. (2009). Development of a pneumatic vibratory wrist for robotic assembly, Robotica. Cambridge University Press, 7(1), pp. 9-16. doi: 10.1017/S0263574700004987.

[16] Kolchugin E.I. (2011). Improving the efficiency of robotic assembly of cylindrical joints the use of passive adaptation and low-frequency vibrations. Dissertation of the candidate of technical sciences. Moscow: Moscow State Technical University, 2011, p. 159.

[17] Bozhkova L.V., Vartanov M.V., Kolchugin E.I. (2009). Experimental setup for robotic assembly on the basis of passive adaptation and low-frequency oscillations. Assembling in mechanical engineering, instrument making. 2009, No. 1, pp. 5-7.

[18]Vartanov, M.V., Bojkova, L.V., Zinina, N.N. (2017): Mathematical model of robotic assembly by means of adaptation and low-frequency vibration, Assembly Automation, Vol. 37 No. 1, pp. 130134. https://doi.org/10.1108/AA-04-2016-036

[19] Vartanov M.V. and Chan Chung Ta. (2020). Mathematical model of a robotic assembly in the presence of gripper rotation and low-frequency vibrations. Assembly in mechanical engineering, instrument making, No. 07, 2020, https://doi. org/10.36652/0202-3350-2020-21-7-299-304

[20]Volkomorov V.I., Markov A.V. (2012). Technology of robotic production. Baltic State Technical University. St. Petersburg 2012, pp. 93-94. http://n2.insu.ru/manuals/1494851692.pdf

[21] Davydova N.S., Simakov A.L. (2008). Analysis of search trajectories of movement in the means of adaptation of parts for automated assembly. Scientific and technical and production journal "Assembly in mechanical engineering, instrument making" 12-2008 (101), p. 9-13.

[22] Mikhail Polishchuk (2019). Anthropomorphic gripping device for an industrial robot: design and calculation of parameters, Springer Nature Applied Sciences (2019) 1:503. https://doi.org/10.1007/s 42452-019-0535-z

[23] Polishchuk M., Tkach M. (2020). Mobile Robot with an Anthropomorphic Walking Device: Design and Simulation. FME Transactions.Volume 48, No 1, 2020. P. 13-20.

[24] Plyaskin I.I. (1982). Optimization of technical solutions in mechanical engineering. M.: Mechanical Engineering, 1982. 176p.

[25] Khamkhanov K.M. (2019). The basics of experiment planning. East Siberian State Technological University.Internet resource. URL: http://window .edu.ru/resource/438/18438/files/Mtdukm8.pdf (date of the application) 2019/08/28).

[26] Korn G., Korn T. (1984). Handbook of Mathematics for Scientists and Engineers. Moscow: Publishing house "Science", 1984. 831p.

\section{ЕКСПЕРИМЕНТАЛНО ИСТРАЖИВАЊЕ РОБОТСКОГ СКЛАПАЊА ПРЕЦИЗНИХ ДЕЛОВА}

\section{М. Полишчук, М. Ткач}

Роботизација процеса склапања се данас остварује коришћењем индустријских робота са високом прецизношћу позиционирања у комбинацији са тактилним средствима прилагођавања условима склапања прецизних делова. Цена таквих робота је знатно већа у поређењу са ценом једноставних робота са руком која има малу прецизност позиционирања. Циљ истраживања је да се смање трошкови процеса склапања корекцијом позиције повезаних делова али не помоћу роботске руке, већ коришћењем додатног технолошког модула монтираног на манипулатору једноставног робота, који ће великом брзином да скенира стохастичка одступања делова који се склапају.

Приказани су резултати потпуног факторског плана експеримента процеса прецизног спајања цилиндричних делова са зазором који није био већи од 3...5 микрона. Предлаже се регресиони модел овог процеса, формула за израчунавање квазиоптималних режима прецизног склапања и графичко-аналитичке зависне вредности времена склапања у режиму скенирања одступања код предмета који се склапају. Предложени брзи метод за компензацију грешке позиционирања код робота омогућава склапање прецизних делова у кратком временском периоду (1...3 сек.). Економски учинак је у томе што уређај за скенирање одступања код склапања прецизних делова, који је монтиран на руци јефтиног робота за малом прецизношћу позиционирања, може знатно да повећа брзину склапања и смањи инвестиције у роботско склапање делова велике прецизности. 